\title{
Estudo imunológico e genético de 10 isolados do vírus da raiva de morcegos do Rio de Janeiro, Sudeste do Brasil
}

Carla da Silva MOTA ${ }^{1}$

Fumio Honma ITO'

Marlon Vicente SILVA ${ }^{2}$

Go SATO ${ }^{3}$

Yuki KOBAYASHI ${ }^{3}$

Takuya ITOU ${ }^{3}$

Takeo SAKAI ${ }^{3}$

Correspondência para:

Carla da Silva Mota, 450, Sherbrooke

Est., ap. 1201, Québec, Montréal,

Canada - H2L 1 J8

carla.mota1976@hotmail.com

Recebido para publicação: 19/02/2009 Aprovado para publicação: 07/01/2010

\author{
1- Departamento de Medicina Veterinária Preventiva e Saúde Animal da \\ Faculdade de Medicina Veterinária e Zootecnia da Universidade de São \\ Paulo, São Paulo-SP \\ 2- Laboratório de Diagnóstico da Raiva do Instituto Municipal de Medicina \\ Veterinária Jorge Vaitsman, Rio de Janeiro-RJ \\ 3- Veterinary Research Center of Department of Preventive Veterinary \\ Medicine and Animal Health, College of Bioresource Sciences, Fujisawa, \\ Kanagawa, Japan
}

\section{Resumo}

O presente trabalho visou estudar dez isolados de vírus da raiva de morcegos hematófagos e não-hematófagos do Estado do Rio de Janeiro em suas características genéticas quanto aos genes N e G. Além disso, estudou-se a resposta de camundongos vacinados com a vacina antirrábica produzida pela replicação da amostra PitmanMoore em cultivo celular, frente ao desafio com estes isolados virais, utilizando-se um ensaio imunológico baseado no teste de potência $N I H$. A vacina antirrábica utilizada na imunização dos camundongos ofereceu proteção em mais de $80 \%$ dos camundongos vacinados com a diluição 1:5 da vacina, frente à maioria dos isolados. A análise filogenética do gene da proteína $\mathrm{N}$ apresentou um padrão de agregação dividido em variante de morcego hematófago e variante de morcego insetívoro, com todos os isolados de morcegos frugívoros Artibeus $s p$. tendo sido segregados com a variante característica de morcegos Desmodus rotundus. Foram observadas diferenças filogenéticas entre as variantes do vírus da raiva de morcego hematófago isoladas na Região Noroeste do Estado do Rio de Janeiro e aquelas isoladas nas Regiōes Metropolitana e Sul do Estado. A substituição do resíduo ácido aspártico por ácido glutâmico na posição 118 , encontradas na caracterização genética da proteína G dos isolados 704/97BR-DR e 151/98BR-DR, permite inferir que esta posição esteja relacionada à antigenicidade viral. Não foram observadas diferenças genéticas temporais entre os isolados estudados. A vacina antirrábica utilizada ofereceu proteção satisfatória contra a maioria dos isolados estudados.

\section{Introdução}

A raiva continua representando um importante problema de saúde pública em todo o mundo, a despeito de todos os avanços científicos desde a sua descoberta na Antiguidade e da disponibilidade de vacinas efetivas para uso humano e animal, por sua evoluçáo frequentemente fatal e pelo elevado número anual de casos em humanos e em animais ${ }^{1}$.
Palavras-chave: Vírus da raiva. Vacina antirrábica. Potência de vacinas. Morcegos. Filogenia.
Os reservatórios mais conhecidos e considerados eficientes na transmissão da raiva sempre foram espécies da ordem Carnivora ${ }^{2}$. Entretanto, no Brasil, os morcegos apresentam-se como transmissores emergentes, em função do aumento do número de casos registrados de raiva humana transmitida por morcegos ${ }^{3}$, notadamente nas regióes norte e nordeste do país ${ }^{4}$, e da crescente invasão de morcegos hematófagos e 
não-hematófagos nas áreas urbanas provocada pela adaptação a abrigos artificiais ${ }^{5}$.

As vacinas antirrábicas disponíveis para uso em humanos e animais são todas de vírus inativado ${ }^{6}$. Atualmente, a vacina utilizada nos programas de saúde pública no Brasil é a vacina produzida a partir da replicação da amostra WISTAR PM/WI 38-1503M em cultura de células Vero ${ }^{7}$. Para determinar a capacidade de um lote de vacina antirrábica em induzir proteção, o teste de potência NIH, realizado pela vacinação seriada de lotes de camundongos, seguida de desafio viral com o isolado padrão, é considerado o ensaio padrão-ouro ${ }^{8}$.

Considerando-se o potencial de casos de raiva humana transmitida por morcegos hematófagos e não-hematófagos em função de sua crescente proximidade ao ambiente urbano, este trabalho teve por objetivo estudar o efeito do desafio de camundongos previamente vacinados com a vacina antirrábica humana, frente a isolados de morcegos e a diversidade genética destes isolados quanto ao gene da proteína $\mathrm{N}$ e ao gene da proteína $\mathrm{G}$.

\section{Materiais e Métodos}

Foram utilizados camundongos albinos suíços recém-desmamados, pesando entre 13-16 g, provenientes do Biotério do
Instituto Municipal de Medicina Veterinária Jorge Vaitsman (IMMVJV). Seu uso foi autorizado pela Comissão de Bioética da Faculdade de Medicina Veterinária e Zootecnia da Universidade de Sáo Paulo, protocolo n ${ }^{\circ}$ 532/2004.

Foi utilizada a amostra padrão do vírus da raiva CVS-37, além de outros 10 isolados do vírus da raiva de morcegos hematófagos e não-hematófagos, oriundos de seis Municípios do Estado do Rio de Janeiro, conforme os dados resumidos no quadro $1 \mathrm{e}$ ilustrados na figura 1 .

Utilizou-se a vacina antirrábicahumana produzida a partir da replicação da amostra WISTAR PM/WI 38-1503M em cultura de células Vero, inativada pela betapropriolactona, pelo laboratório Aventis Pasteur (Lyon, França), e gentilmente cedida pela Secretaria Municipal de Saúde do Estado do Rio de Janeiro.

Camundongos previamente vacinados com a vacina antirrábica humana foram submetidos ao desafio viral com o vírus padráo CVS-37 e com os isolados de morcegos, em um ensaio imunológico realizado à semelhança do teste $\mathrm{NIH}^{8}$. A vacina antirrábica foi diluída a 1:5, 1:25 e 1:125. Para cada diluição foi vacinado um grupo de 16 camundongos, por via intraperitoneal, com $0,5 \mathrm{~mL}$ da vacina diluída, perfazendo um total de duas doses,

\begin{tabular}{|c|c|c|c|}
\hline ISOLADO & ANO & ESPÉCIE ANIMAL & MUNICÍPIO \\
\hline 222/90BR-T & 1990 & Tadarida sp. & Rio de Janeiro \\
\hline 419/90BR-T & 1990 & Tadarida sp. & Rio de Janeiro \\
\hline 704/97BR-DR & 1997 & Desmodus rotundus & Itaperuna \\
\hline 151/98BR-DR & 1998 & Desmodus rotundus & Laje do Muriaé \\
\hline 204/01BR-AL & 2001 & Artibeus lituratus & Rio de Janeiro \\
\hline 399/02BR-AF & 2002 & Artibeus fimbriatus & Rio de Janeiro \\
\hline 624/02BR-DR & 2002 & Desmodus rotundus & Valença \\
\hline 755/02BR-A & 2002 & Artibeus sp. & Paracambi \\
\hline 046/04BR-NL & 2004 & Nyctinomops laticaudatus & Rio de Janeiro \\
\hline 384/04BR-A & 2004 & Artibeus sp. & Mesquita \\
\hline
\end{tabular}

Quadro 1- Dados descritivos dos isolados do vírus da raiva obtidos de morcegos recebidos na Seção de Diagnóstico de Raiva do Instituto Municipal de Medicina Veterinária "Jorge Vaitsman" (IMMVJV) - Rio de Janeiro $-1990-2004$ 
Rio de Janeiro - LS $22^{\circ} 54^{\prime} 10^{\prime \prime}$ LO $43^{\circ} 12^{\prime} 27^{\prime \prime}$

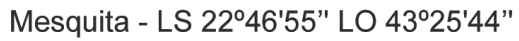

Paracambi - LS 22 $2^{\circ} 36^{\prime} 39^{\prime \prime}$ LO $43^{\circ} 42^{\prime} 33^{\prime \prime}$

Valença - LS $22^{\circ} 14 ' 44^{\prime \prime}$ LO $43^{\circ} 42^{\prime} 01^{\prime \prime}$

Laje do Muriaé - LS 21012'23" LO 42007'21"

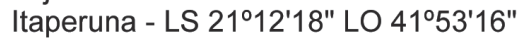

\author{
(n)
}

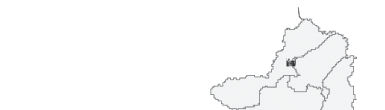

ESPÍRITO SANTO

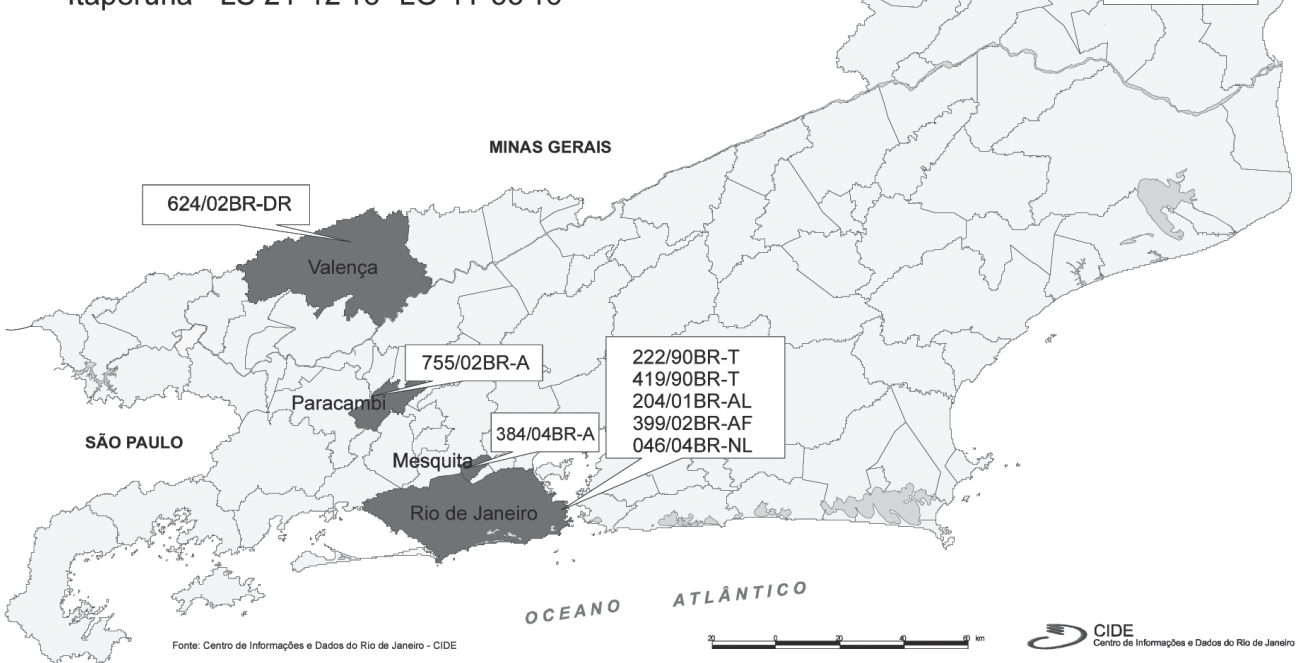

Figura 1- Mapa do Estado do Rio de Janeiro, destacando os Municípios de origem dos isolados utilizados neste trabalhoz. Centro de Informações e Dados do Rio de Janeiro - CIDE

administradas com um intervalo de sete dias. O desafio viral foi realizado 14 dias após a primeira vacinação, por via intracerebral, com um volume de $0,03 \mathrm{~mL}$ da suspensão do vírus-desafio, para cada um dos dez isolados estudados. $\mathrm{O}$ controle desta suspensão foi realizado por meio de sua titulação em camundongos não-vacinados, devendo a dose desafio se encontrar na faixa entre 12 a 50 $\mathrm{DL}_{50}$ para o ensaio ser considerado válido. Os animais inoculados foram observados por 14 dias, à procura de sinais clínicos da raiva. Foram realizados o cálculo da Dose Efetiva $50 \%\left(\mathrm{DE}_{50} / 0,5 \mathrm{~mL}\right)$ com o teste de Probito, com o uso do programa StatsDirect Statistical Software versão 2.6.2, com intervalo de confiança de 95\%; e o cálculo da Dose Protetora $50 \%\left(\mathrm{DP}_{50} / 0,5 \mathrm{~mL}\right)$ com o método de Reed e Müench'.

A extração de RNA, PCR e sequenciamento foram realizados conforme metodologia descrita ${ }^{10,11}$. Para o RT-PCR e sequenciamento do gene das proteínas $\mathrm{G}$ e $\mathrm{N}$ foram utilizados os primers relacionados nos quadros 2 e 3, respectivamente. Para os isolados sequenciados quanto ao gene da proteina $\mathrm{N}$, as sequências de nucleotídeos consensuais de cada isolado foram alinhados pelo método CLUSTAL W, com o uso do programa BioEdit Sequence Alignment Editor versão 7.0.5.2 $2^{12}$. Para a construção da árvore filogenética foi utilizado o programa Molecular Evolutionary Genetics Analysis - MEGA, versão 3.113, com o algoritmo de Neighbor-Joining, modelo evolutivo Kimura-2-parâmetros e bootstrap com 1000 replicaçóes. Para os isolados sequenciados quanto ao gene da proteina $G$, cada sequência nucleotídica foi traduzida em resíduos de aminoácidos e comparadas manualmente com o uso do programa BioEdit Sequence Alignemt Editor versão 7.0.5.2. 


\begin{tabular}{|c|c|c|c|}
\hline Primers & Sentido & Posição ${ }^{1}$ & Sequência \\
\hline Ga3222-40 & + & $3221-3229$ & 5'CGCTGCATTTT(A/G)TCA(A/G)AGT3' \\
\hline VT129 & - & $3438-3419$ & 5'GGTGATGTATATCGATGGGG3' \\
\hline Ga3222-40-1 & + & $3518-3536$ & 5'GGGATACATCTCTGCСАTA3' \\
\hline Gb4119-39-1 & - & 3819-3801 & 5'GGGATTTGTCGTATGGGTC3' \\
\hline GS3994 & + & $3995-4019$ & 5'CGG(A/C)TTTGTGGATGAAAG(A/G)GGC3' \\
\hline Gb4119-39 & - & $4135-4116$ & 5'GGAGGGCACCATTTGGT(A/C)TC3' \\
\hline GS3994-1 & + & $4373-4392$ & 5'GACTTGGAACGAGATCATCC3' \\
\hline VT1391 & - & $4700-4681$ & 5'CAGGAGATATTTCCCCCAAC3' \\
\hline RVLa-5 & - & $4857-4836$ & 5'CCCA(C/G)GAAGATAT(A/G)ACTTTCCC3' \\
\hline VT1551 & + & $4852-4859$ & 5'GTCGTATCTTCATGGGAG3' \\
\hline G-antiBR2072-1 & - & 4996-4978 & 5'CATGAAGTATGTGAAGGGC3' \\
\hline RVLa-3 & - & $5114-5091$ & 5'GCACCATTGGT(C/T)ACTGATACTGTC3' \\
\hline G-antiBR2072 & - & $5375-5356$ & 5'TGCTGATTGC(A/G)CCTACATT3' \\
\hline RVLa-1 & - & $5435-5416$ & 5'AT(A/G)GGGTCATCATAAACCTC3' \\
\hline
\end{tabular}

${ }^{1}$ Numeração nucleotídica baseada na sequência do isolado PV (GenBank n. M13215)

Quadro 2- Descrição dos primers utilizados para o RT-PCR e para o sequenciamento genético dos isolados quanto ao gene da proteína $\mathrm{G}$

\begin{tabular}{|c|c|c|l|}
\hline Primers & Sentido & Posição $^{1}$ & \multicolumn{1}{|c|}{ Sequência } \\
\hline P1 & + & $66-86$ & 5'CTACAATGGATGCCGACAAGA3' $^{\prime}$ \\
\hline N8 & - & $1585-1568$ & 5'AGTTTCTTCAGCCATCTC3' \\
\hline BRABN-S1 & + & $336-355$ & 5'GGACTAGCTATGGAATCCTG3' \\
\hline BRABN-S3 & + & $782-801$ & 5'GGACTGGTGTCATTTACAGG3' \\
\hline BRABN-C3 & - & $537-519$ & 5'TGTCCAGAGATTTTGCTCA3' \\
\hline P2 & - & $1029-1007$ & 5'CCCATATAACATCCAACAAAGTG3' \\
\hline
\end{tabular}

1 Numeração nucleotídica baseada na sequência do isolado PV (GenBank n. M13215)

Quadro 3- Descrição dos primers utilizados para o RT-PCR e para o sequenciamento genético dos isolados quanto ao gene da proteína $\mathrm{N}$

\section{Resultados}

Os resultados dos ensaios imunológicos realizados com base no protocolo do teste de potência da vacina antirrábica humana (NIH), com os isolados do vírus da raiva de morcegos e vírus padrão CVS, estão apresentados na tabela 1. Dos camundongos vacinados com a vacina antirrábica de uso humano, diluída 1:5, a proteção conferida pela vacina foi maior que $80 \%$ para a maioria dos isolados do vírus da raiva utilizados no desafio viral dos ensaios imunológicos, à exceção dos isolados
704/97BR-DR, 151/98BR-DR, 399/02BRAF e 624/02BR-DR.

No desafio viral realizado com a amostra padrāo CVS, a proteção conferida pela vacina antirrábica humana (teste) foi maior que $80 \%$, nos três grupos de camundongos vacinados com diluiçóes diferentes da vacina. Para a vacina antirrábica de referência, cujo ensaio NIH foi realizado no mesmo momento do ensaio com a vacina teste e com a mesma suspensão de vírus-desafio, $81,25 \%$ dos camundongos vacinados foram protegidos na diluição 1:5 
da vacina, $68,75 \%$ na diluição $1: 25$ e 43,75\% na diluição 1:125. A tabela 2 apresenta os resultados dos ensaios imunológicos em Dose Efetiva $50 \%$ por $0,5 \mathrm{~mL}$ de vacina, calculada por meio do teste de Probito; a Dose Protetora a $50 \%$ por $0,5 \mathrm{~mL}$ de vacina e as Dose Letal $50 \%$ por $0,03 \mathrm{~mL}$ do vírus-desafio, ambas calculadas pelo método de Reed e Müench ${ }^{9}$. Para os isolados 151/98BR-DR, 399/02BR-AF e 624/02BR-DR, o teste de Probito não foi capaz de fornecer resultados com intervalo de confiança de $95 \%$ porque o número de animais sobreviventes foi igual em diluiçóes diferentes da vacina. Para o vírus padrão CVS, o teste também não produziu resultados em função do número de animais sobreviventes ter sido elevado e próximo entre diluiçóes diferentes da vacina.

Os resultados mais baixos da $\mathrm{DP}_{50}$ foram encontrados para os isolados 704/97BR-DR, 151/98BR-DR e 624/02BR$\mathrm{DR}$, oriundos de morcegos hematófagos. Para os isolados 384/04 e vírus padrão CVS não foi possível calcular o valor exato da $\mathrm{DP}_{50}$, pois o acumulado de camundongos sobreviventes foi superior a $50 \%$ para todas as diluiçóes

Tabela 1- Resultados dos ensaios imunológicos em valores absolutos e percentuais dos camundongos sobreviventes, por diluição da vacina antirrábica, de acordo com o isolado utilizado para o desafio viral, realizado na Seção de Diagnóstico de Raiva do IMMVJV - Rio de Janeiro - 2005-2007

\begin{tabular}{|c|c|c|c|}
\hline \multirow{2}{*}{ Isolado viral } & \multicolumn{3}{|c|}{ Diluição da vacina } \\
\hline & 1:5 & $1: 25$ & $1: 125$ \\
\hline 222/90BR-T & $\begin{array}{c}15 / 16^{1} \\
93,8 \%\end{array}$ & $\begin{array}{c}8 / 16 \\
\mathbf{5 0 , 0 \%}\end{array}$ & $\begin{array}{c}8 / 16 \\
\mathbf{5 0 , 0 \%}\end{array}$ \\
\hline 419/90BR-T & $\begin{array}{r}15 / 16 \\
\mathbf{9 3 , 8 \%}\end{array}$ & $\begin{array}{r}10 / 16 \\
62,5 \%\end{array}$ & $\begin{array}{c}5 / 16 \\
\mathbf{3 1 , 3 \%}\end{array}$ \\
\hline 704/97BR-DR & $\begin{array}{c}9 / 7 \\
56,3 \%\end{array}$ & $\begin{array}{c}2 / 14 \\
12,5 \%\end{array}$ & $\begin{array}{l}0 / 16 \\
\mathbf{0 , 0} \%\end{array}$ \\
\hline 151/98BR-DR & $\begin{array}{c}7 / 16 \\
43,8 \%\end{array}$ & $\begin{array}{c}7 / 16 \\
43,8 \%\end{array}$ & $\begin{array}{c}4 / 16 \\
25,0 \%\end{array}$ \\
\hline 204/01BR-AL & $\begin{array}{r}14 / 16 \\
\mathbf{8 7 , 5} \%\end{array}$ & $\begin{array}{r}12 / 16 \\
75,0 \%\end{array}$ & $\begin{array}{c}9 / 16 \\
\mathbf{5 6 , 3 \%}\end{array}$ \\
\hline 399/02BR-AF & $\begin{array}{r}11 / 16 \\
\mathbf{6 8 , 8} \%\end{array}$ & $\begin{array}{r}11 / 16 \\
\mathbf{6 8 , 8} \%\end{array}$ & $\begin{array}{c}8 / 16 \\
\mathbf{5 0 , 0 \%}\end{array}$ \\
\hline 624/02BR-DR & $\begin{array}{r}10 / 16 \\
62,5 \%\end{array}$ & $\begin{array}{c}6 / 16 \\
37,5 \%\end{array}$ & $\begin{array}{c}6 / 16 \\
37,5 \%\end{array}$ \\
\hline 755/02BR-A & $\begin{array}{r}14 / 16 \\
\mathbf{8 7 , 5} \%\end{array}$ & $\begin{array}{c}7 / 16 \\
43,8 \%\end{array}$ & $\begin{array}{c}5 / 16 \\
\mathbf{3 1 , 3 \%}\end{array}$ \\
\hline 046/04BR-NL & $\begin{array}{c}16 / 16 \\
\mathbf{1 0 0 , 0} \%\end{array}$ & $\begin{array}{r}11 / 16 \\
68,8 \%\end{array}$ & $\begin{array}{c}6 / 16 \\
37,5 \%\end{array}$ \\
\hline 384/04BR-A & $\begin{array}{r}15 / 16 \\
\mathbf{9 3 , 8 \%}\end{array}$ & $\begin{array}{r}14 / 16 \\
\mathbf{8 7 , 5} \%\end{array}$ & $\begin{array}{r}10 / 16 \\
62,5 \%\end{array}$ \\
\hline Amostra CVS & $\begin{array}{c}16 / 16 \\
\mathbf{1 0 0 , 0} \%\end{array}$ & $\begin{array}{r}15 / 16 \\
93,8 \%\end{array}$ & $\begin{array}{r}13 / 16 \\
\mathbf{8 1 , 3 \%}\end{array}$ \\
\hline
\end{tabular}

${ }^{1}$ Sobreviventes/Animais desafiados

2 Percentual de sobreviventes 
Tabela 2- Resultados das $\mathrm{DE}_{50}$ calculadas por Probito, e das $\mathrm{DP}_{50}$ calculadas pelo método Reed e Müench e obtidas a partir do desafio viral $\left(\mathrm{DL}_{50}\right)$ dos camundongos vacinados com a vacina antirrábica de uso humano, utilizando-se o vírus da raiva padrão CVS e os isolados oriundos de morcegos, realizado na Seção de Diagnóstico de Raiva do IMMVJV - Rio de Janeiro - 2007-2008

\begin{tabular}{cccc}
\hline ISOLADOS & $\begin{array}{c}\mathbf{D E}_{50} / \mathbf{0 , 5} \mathbf{~ m L} \\
\text { (PROBITO) }\end{array}$ & $\begin{array}{c}\text { DP }_{\mathbf{5 0}} / \mathbf{0}, \mathbf{5 m L} \\
\text { (REED E MÜENCH) }\end{array}$ & $\begin{array}{c}\text { DL }_{\mathbf{5 0}} / \mathbf{0 , 0 3} \mathbf{~ m L} \\
\text { (REED E MÜENCH) }\end{array}$ \\
\hline 222/90BR-T & $1: 73$ & $1: 51$ & 14,54 \\
419/90BR-T & $1: 49$ & $1: 47$ & 17,78 \\
704/97BR-DR & $1: 6$ & $1: 7$ & 31,62 \\
151/98BR-DR & - & $1: 13$ & 50,69 \\
204/01BR-AL & $1: 224$ & $1: 84$ & 13,33 \\
399/02BR-AF & - & $1: 51$ & 56,23 \\
624/02BR-DR & - & $1: 18$ & 13,33 \\
755/02BR-A & $1: 33$ & $1: 28$ & 42,17 \\
046/04BR-NL & $z 1: 75$ & $1: 62$ & 23,71 \\
384/04BR-A & $1: 312$ & $>1: 125$ & 36,30 \\
Amostra CVS & - & $>1: 125$ & 18,62 \\
\hline
\end{tabular}

(-) O teste não forneceu resultados com intervalo de confiança de $95 \%$.

da vacina. Para os ensaios imunológicos realizados com os isolados 204/01BR-AL e 624/02BR-DR, para uma mesma dosedesafio, a vacina apresesentou resultado 4,6 vezes superior frente ao isolado 204/01BRAL. De modo semelhante, o ensaio com o vírus padrão CVS apresentou resultado pelo menos duas vezes superior ao realizado com o isolado 419/90BR-T. Por outro lado, com o isolado 704/97BR-DR, geneticamente relacionado ao isolado 151/98BR-DR, a vacina apresentou resultado inferior, frente uma dose menor do vírus-desafio.

Comparando-se o gene $\mathrm{N}$ dos isolados do vírus da raiva de morcegos estudados neste trabalho com outros isolados do Brasil, a relação filogenética estabelecida segregou os isolados em dois grupos distintos: variante de morcego hematófago e variante de morcego insetívoro, conforme ilustrado na figura 2. As amostras 204/01BR-AL, 399/02BR-AF, 755/02BR-A e 384/04, todas obtidas de morcegos Artibeus sp. segregaram com a variante de característica de morcego hematófago Desmodus rotundus. Os isolados 704/97BR-DR e 151/98BR$\mathrm{DR}$, oriundos de morcegos $D$. rotundus na Região Noroeste do Estado do Rio de Janeiro e que apresentaram resultados semelhantes no ensaio imunológico, formaram um agrupamento à parte sustentado por um valor de bootstrap de 100, com base na sequência de 1,575 bp do gene da proteína G (Figura 3).

A regiâo do ectodomínio do gene da proteína $\mathrm{G}$ dos isolados do vírus da raiva de morcegos apresenta-se mais conservada, com $89,75 \%$ de identidade entre os aminoácidos, enquanto a região do peptídeo de sinal apresenta $63,15 \%$ de identidade, seguida da regiáo do endodomínio com 38,63\% e o domínio transmembrana com 33,33\%, quando comparado ao isolado vacinal Pitman-Moore. Os três isolados de morcegos insetívoros (222/90BR-T, 419/90BR-T e 046/04BR-NL) apresentaram o mesmo padrão de substituiçóes de aminoácidos, à exceção de uma substituição de uma serina por uma fenilalanina na posição 391 do isolado 419/90BR-T. Algumas destas substituições estão presentes nas regiōes II b (posição 37), II (posição 147), II a (posição 199), "wb+" (posição 264) e III (posição 330), que são sítios antigênicos e epítopos. A substituição de uma citosina (amostras PM e CVS)/timina (isolado PV) por uma guanina na posição 392 da sequência de nucleotídeos dos isolados 704/97BR-DR e 158/98, determinou a substituição do aminoácido ácido aspártico pelo ácido glutâmico (Figura 4). 


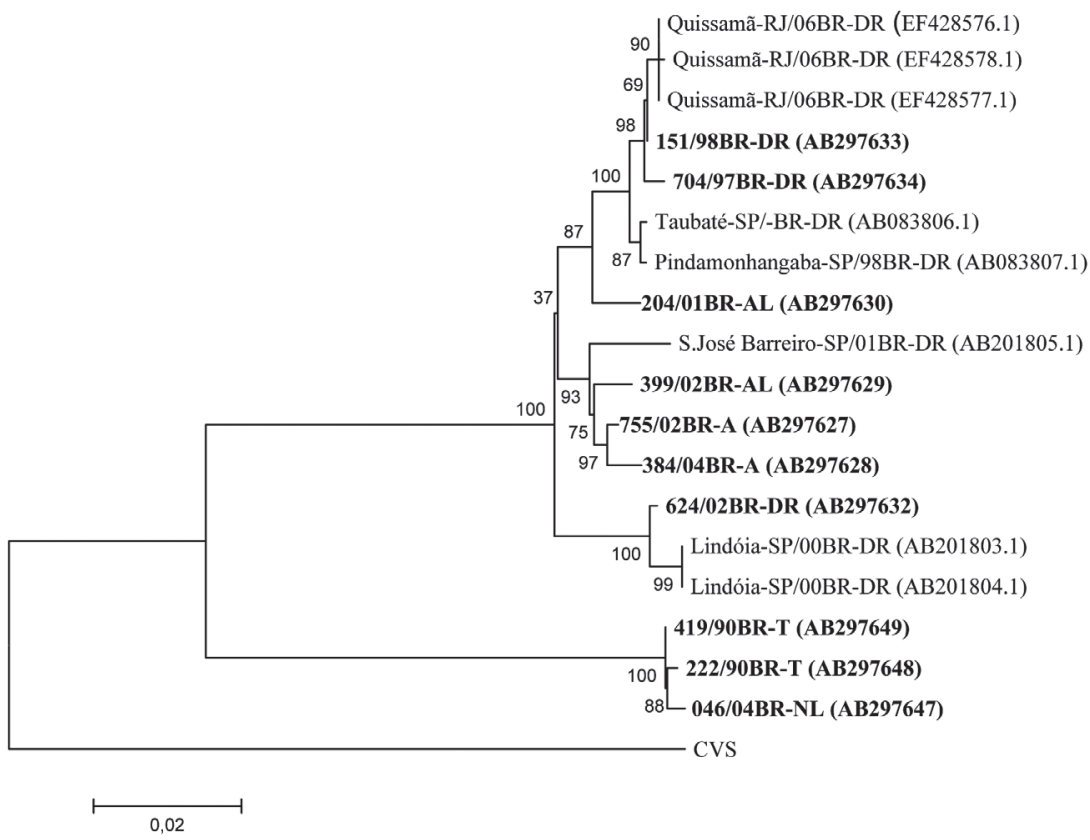

Figura 2- Dendograma da relação filogenética estabelecida entre os isolados do vírus da raiva de morcegos obtidos na Seção de Diagnóstico de Raiva do IMMVJV (em negrito) e de outros isolados de morcegos, com base na sequência de 1,353 bp do gene da proteína $\mathrm{N}$ - Rio de Janeiro - 2007-2008

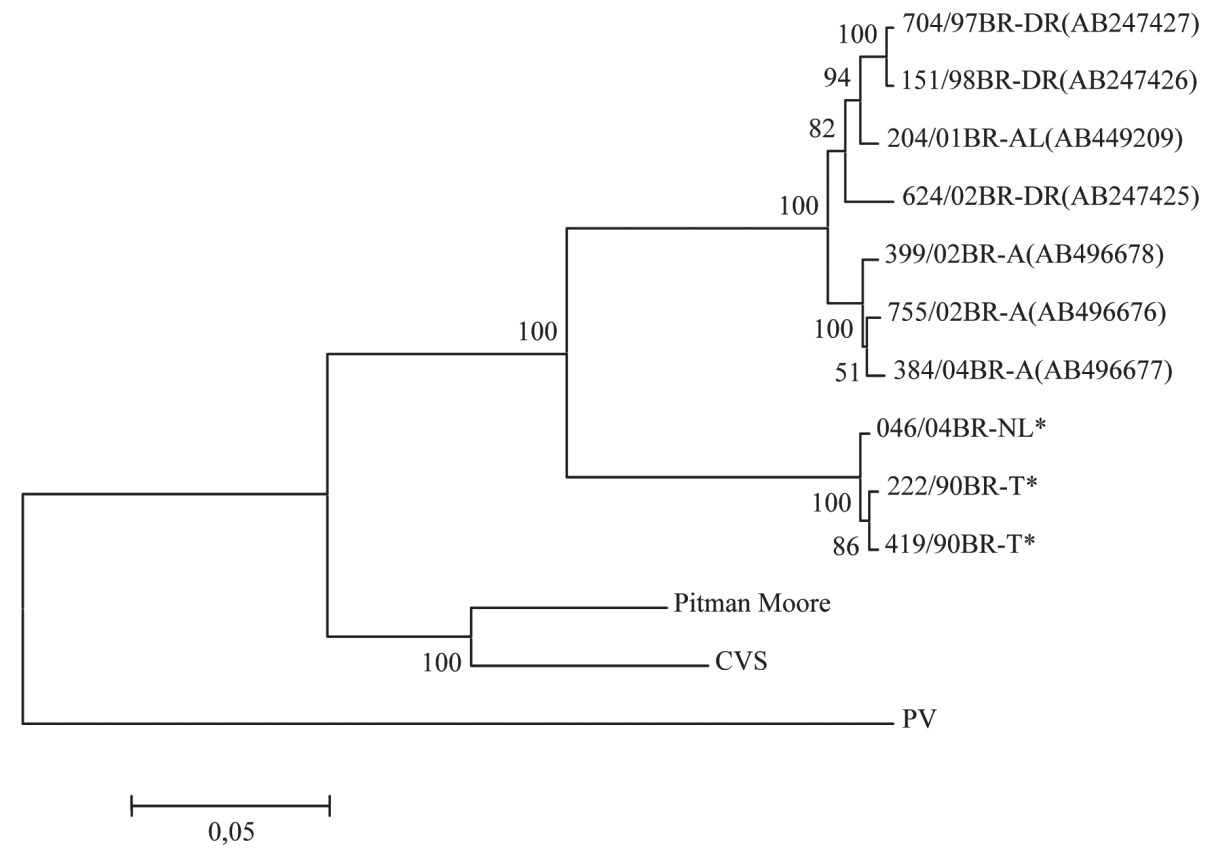

Figura 3- Dendograma da relação filogenética estabelecida entre os isolados do vírus da raiva de morcegos obtidos na Seção de Diagnóstico de Raiva do IMMVJV e o vírus padrão CVS, Pitman Moore e PV, com base na sequência de 1,575 bp do gene da proteína G - Rio de Janeiro - 2007-2008 *Acesso GenBank não disponível 
Isolados

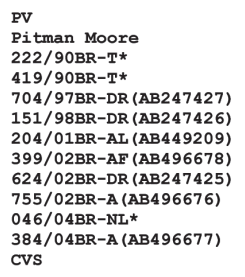

$\mathrm{PV}$

Pitman Moore $222 / 90 \mathrm{BR}-\mathrm{T}^{*}$
$419 / 90 \mathrm{BR}-\mathrm{T}^{*}$

704/97BR-DR (AB247427)

704/97BR-DR (AB247427)

151/98BR-DR (AB247426)

399/02BR-AF (AB496678)

624/02BR-DR (AB247425)

755/02BR-DR (AB247425)

$046 / 04 \mathrm{BR}_{\mathrm{R}}-\mathrm{NL}^{*}$

384/04BR-A (AB496677)

cvs

PV

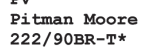

222/90BR-T*

419/90BR-T*

704/97BR-DR (AB24 7427)

151/98BR-DR (AB247426)

204/01BR-AL (AB449209)

(9)

$755 / 02 B R-A(A B 496676)$

046/04BR-NL*

384/04BR-A (AB496677)

CVS

PV

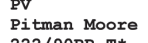

222/90BR-T*

419/90BR-T*

704/97BR-DR (AB247427)

151/98BR-DR (AB247426)

204/01BR-AL (AB44 9209)

399/02BR-AF (AB4 96678)

624/02BR-DR (AB24 7425)

755/02BR-A (AB496676)
046/04BR-NL*

$384 / 04 \mathrm{E}$

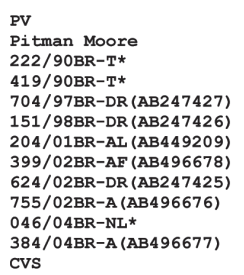

Peptídeo-sinal Ectodomínio $\rightarrow$
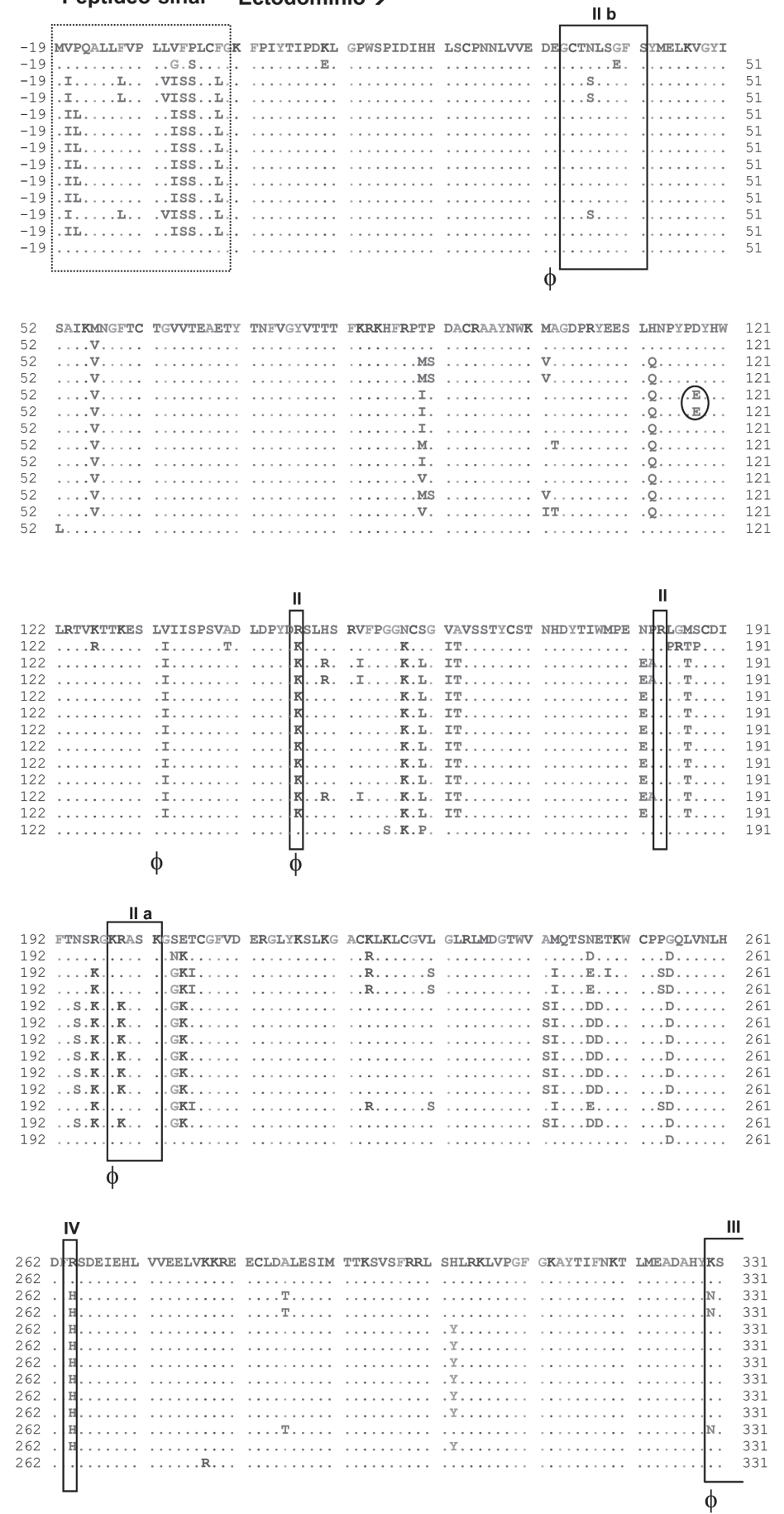

Figura 4- Alinhamento e tradução das sequências de nucleotídeos do gene da proteína G dos isolados do vírus da raiva de morcegos e do vírus padrão CVS, PV e PM. Destaque em linha tracejada para a região do peptídio-sinal e para o domínio transmembrana. Caixas de linha contínua indicam os principais sítios antigênics e epítopos. Phi $(\phi)$ indica os resíduos envolvidos na patogenicidade. Círculo destaca a substituição presente na posição 118 dos isolados 704/97BR-DR e 151/98BR-DR - Rio de Janeiro - 2007-2008 

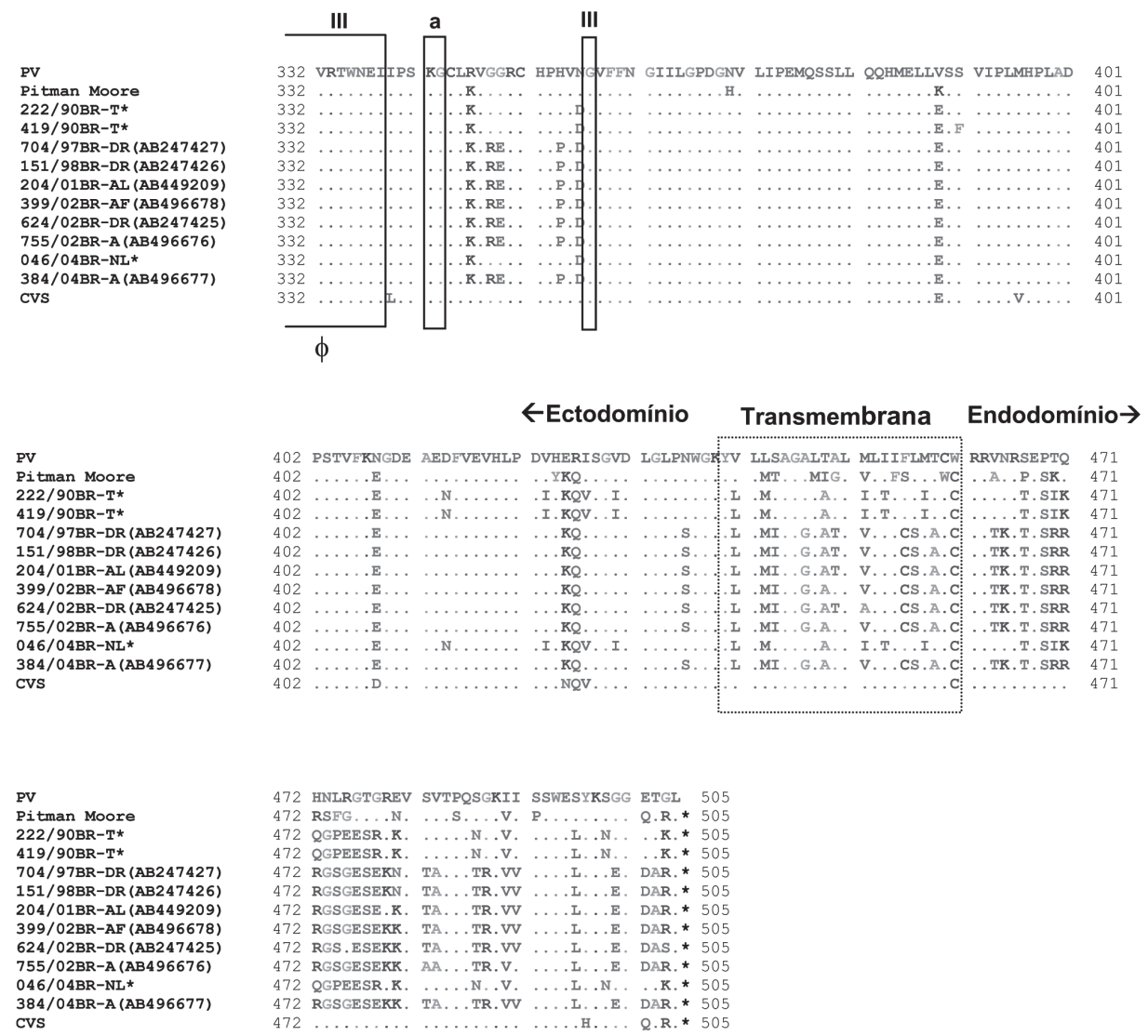

(Conclusão)

Figura 4- Alinhamento e tradução das sequências de nucleotídeos do gene da proteína $\mathrm{G}$ dos isolados do vírus da raiva de morcegos e do vírus padrão CVS, PV e PM. Destaque em linha tracejada para a região do peptídio-sinal e para o domínio transmembrana. Caixas de linha contínua indicam os principais sítios antigênics e epítopos. Phi $(\phi)$ indica os resíduos envolvidos na patogenicidade. Círculo destaca a substituição presente na posição 118 dos isolados 704/97BR-DR e 151/98BR-DR - Rio de Janeiro - 2007-2008

\section{Discussão e Conclusões}

Um dos critérios de validação do teste NIH é a proteção de mais de $70 \%$ dos camundongos vacinados com a diluição $1: 5^{8}$ - valor este que não foi alcançado nos ensaios imunológicos realizados com os isolados 704/97BR-DR, 151/98BR-DR, 399/02BR-AF e 624/02BR-DR, oriundos de morcegos hematófagos. Este resultado está em conformidade com o achado de Bernardi et al. ${ }^{14}$ para uma vacina antirrábica de uso veterinário importada, que não apresentou resultado satisfatório no teste $\mathrm{CDC}$, quando este foi realizado com um isolado de morcego hematófago.
Utilizando a vacina antirrábica de uso humano produzida em células Vero, encontramos $100 \%$ de proteção dos camundongos para o teste NIH realizado com o vírus CVS e, dentre os desafios realizados com os isolados de morcego, a menor proteção encontrada foi de $43,8 \%$ para a diluição $1: 5$ da vacina, quando o isolado utilizado foi o $151 / 98 B R-D R$. Zanetti et al. ${ }^{15}$ avaliaram a atividade protetora da vacina Fuenzalida- Palácios modificada, utilizando como vírus-desafio (30 a 50 $\mathrm{DL}_{50} / 0,03 \mathrm{~mL}$ ) o vírus padrão CVS e outro, oriundo de morcego hematófago, nos testes de Habel e NIH, e verificaram que $94,4 \%$ dos camundongos foram protegidos pela vacina 
diluída a 1:5, no desafio com a amostra CVS e apenas 36,2\% dos camundongos foram protegidos quando o desafio foi realizado com a variante de morcego hematófago.

Em nosso trabalho, a dose de vacina aplicada nos camundogos foi cinco vezes maior que a utilizada por Dietzschold e Hooper ${ }^{16}$ e a dose do vírus-desafio foi cerca de um quinto inferior para os isolados de morcegos insetívoros, os quais apresentaram um percentual de proteção de 93,8\% (222/90BR-T), 93,8\% (419/90BRT) e $100 \%(046 / 04 \mathrm{BR}-\mathrm{NL})$, enquanto estes autores observaram que $100 \%$ dos camundongos foram protegidos com a diluição $1: 5$ da vacina e $30 \%$ com a diluição $1: 125$. Pode-se concluir, então, que as diferenças de proteção observadas em nosso trabalho estáo relacionadas com o isolado viral utilizado, em conformidade com a assertiva de Barth, Diderrich e Weineman ${ }^{17}$ e Zaneti et al. ${ }^{15}$. Em adição, para o ensaio imunológico realizado com os isolados 704/97BR-DR e 151/98BR-DR, relacionados quanto ao gene $G$ e os únicos a apresentarem uma substituição de aminoácido em comum na posiçấo 118 deste gene, verificou-se que, para o desafio com $31,62 \mathrm{DL}_{50}$ do isolado 704/97BR-DR, a $\mathrm{DP}_{50}$ foi inferior à obtida com 50,69 $\mathrm{DL}_{50}$ do isolado 151/98BR-DR.

As árvores filogenéticas dos isolados de morcego, quanto aos genes das proteínas $\mathrm{N}$ e G, apresentaram o padrão de agregação esperado, com a formação de dois grupos distintos denominados variante de morcego hematófago e variante de morcego insetívoro, em concordância com outros autores ${ }^{18,19}$. Os isolados de morcegos Artibeus sp. segregaram com a variante Desmodus rotundus como encontrado em outros estudos ${ }^{20,21}$, o que enfatiza a importância dos morcegos frugívoros como reservatório natural do vírus da raiva.

Em relação ao gene $\mathrm{N}$, os isolados 704/97BR-DR e 151/98BR-DR, da Região Noroeste do Estado do Rio de Janeiro, formaram um agrupamento com isolados procedentes do Município de Quissamá, Norte do Estado, oriundos de morcegos D. rotundus, em 2006. Outros isolados das mesmas regióes apresentaram diferenças no padrão de agrupamento, por estarem em bacias hidrográficas distintas ${ }^{22}$, mas este perfil não foi observado em nosso estudo, nem pelo realizado por Vieira $(2007)^{23}$. O contraste entre os agrupamentos da árvore filogenética construída foi observado entre os isolados das Regióes Noroeste e Sul, visto que o isolado 624/02BR-DR está agrupado com isolados do Município de Lindóia, na Regiáo Norte do Estado de São Paulo.

Como em outros trabalhos ${ }^{24,25}$, não foram encontradas diferenças temporais entre os isolados estudados. O isolado 046/04BR-NL, de 2004, se relaciona com o agrupamento formado pelos isolados 222/90BR-T e 419/90BR-T, de 1990, sustentado por um valor de bootstrap de 100 , quanto aos genes da proteína $\mathrm{G}$ e da proteína N. Em adição, a substituição do aminoácido lisina (posição 330), envolvido na patogenicidade, por um resíduo de asparagina, foi encontrado nas sequências do gene da proteína $\mathrm{G}$ dos três isolados.

Uma correlação entre os dados imunológicos, genéticos e geográficos foi notada entre os isolados 704/97BR-DR e 151/98BR-DR, pois seus resultados no ensaio imunológico foram semelhantes e os mesmos estáo intimamente relacionados quanto às suas sequências da proteína $G$ e quanto à sua localização espacial, a noroeste do Estado do Rio de Janeiro e são, provavelmente, pertencentes ao mesmo surto. Estes isolados foram os únicos a apresentar a substituição de um ácido aspártico por um ácido glutâmico na posição 118 e os únicos em cujos ensaios imunológicos a vacina antirrábica de uso humano apresentou o mais baixo desempenho, podendo-se inferir que esta substituiçáo pode ter alterado a antigenicidade dos isolados.

Em nosso estudo, a única substituição encontrada em um resíduo envolvido na patogenicidade viral está relacionada às três variantes de morcegos insetívoros e foi mesma substituiçáo do isolado mutante desenvolvida por Coulon et al. ${ }^{26}$ que, estudando um mutante do vírus CVS (RK-4), com a substituição do resíduo lisina (posição 330) 
por uma asparagina, verificaram que o vírus mutante apresentou-se altamente patogênico para camundongos adultos. No ensaio biológico, verificou-se que a inoculação intracerebral dos camundongos com o isolado 222/90BR-T determinava sintomatologia clínica com quadro exacerbado de excitação e agressividade, diferente dos outros isolados.
Entretanto, em todos os ensaios imunológicos realizados com estes isolados (222/90BR-T, 419/90BR-T e 046/04BR-NL), o percentual de proteção dos camundongos vacinados com a vacina diluída a 1:5 foi superior a $90 \%$, ressaltando a eficiência da neutralização viral conferida pelos anticorpos induzidos pela vacinação.

\title{
Immunological and genetic study of 10 bat rabies virus isolates from Rio de Janeiro State, Southeast Brazil
}

\begin{abstract}
In the present study we analyzed ten bats rabies viruses isolated from Rio de Janeiro State, focusing on its genetic characteristics from genes $\mathrm{N}$ and $\mathrm{G}$, and also in the response of mice vaccinated with cell-culture rabies vaccine, produced with the Pitman-Moore strain, after viral challenge with bat rabies isolates, using an immunologic essay based on NIH vaccine potency test. The vaccine used conferred protection in more than $80 \%$ of the mice vaccinated with $1: 15$ vaccine dilution, after viral challenge. $\mathrm{N}$ gene genetic analysis divided the rabies virus isolates into haematophagous and insectivorous bat variants, with all isolates from Artibeus sp. frugivorous bats being clustered with the variant characteristic of the Desmodus rotundus vampire bat. Phylogenetic differences between isolates from Northeast Region and those from the Metropolitan and South Regions of Rio de Janeiro State were observed. The substitution of an aspartic acid to a glutamic acid found in the position 118 of $\mathrm{G}$ gene genetic characterization from samples 704/97BR-DR and 151/98BR-DR seems to be related to viral antigenicity. There were no time-related genetic differences between the studied samples. The vaccine employed was found with satisfactory protection against the majority of the isolates used.
\end{abstract}

\section{Referências}

1 WORLD HEALTH ORGANIZATION. WHO expert consultation on rabies. Geneva: WHO Press, 2005. 121 p. (Technical Report Series, n. 931).

2 BRASS, D. A. Rabies in bats: natural history and public health implications. 1. ed. Connecticut: Livia Press, 1994. p. $131-147$

3 BRASIL. Ministério da Saúde. Surto de raiva humana transmitida por morcegos no município de Portel-Pará, Março/Abril de 2004. Boletim Eletrônico Epidemiológico, v. 4, n. 6, p. 5, 2004.

4 ROSA, E. S. T. da; KOTAIT, I.; BARBOSA, T. F. S.; CARRIERI, M. L.; BRANDÃO, P. E.; PINHEIRO, A. S.; BEGOT, A. L.; WADA, M. Y.; OLIVEIRA, R. C. de; GRISARD, E. C.; FERREIRA, M.; LIMA, R. J. S.; MONTEBELLO, L.; MEDEIROS, D. B. A.; SOUSA, R. C.
Keywords:

Rabies virus. Rabies vaccine. Vaccine Potency. Bats. Phylogeny.
M.; BENSABATH, G.; CARMO, E. H.; VASCONCELOS, P. F. C. Bat-transmitted human rabies outbreaks, Brazilian Amazon. Emerging Infectious Diseases, v. 12 n. 8, p. 1197-1202, 2006.

5 ÉSBERARD, C. Morcegos urbanos no Rio de Janeiro. In: KOTAIT, I.; TAKAOKA, N. Y.; PANACHAO, M. R. I.; SODRÉ, M. M. Manejo de quirópteros em áreas urbanas. São Paulo: Instituto Pasteur, 2003. p. 28-32. (Manual Técnico do Instituto Pasteur, 7).

6- WORLD HEALTH ORGANIZATION. Rabies vaccines. Weekly Epidemiological Record, v. 14, n. 77, p. 109-120, 2002.

7 COSTA, W. A.; ÁVILA, C. A.; VALENTINE, E. J. G. REICHMANN, M. L. A. B.; CUNHA, R. S.; GUIDOLIN, R.; PANACHÃO, M. R. L.; OMOTO, T. M.; BOLZAN, V. L. Profilaxia da raiva humana. 2. ed. São Paulo: Instituto Pasteur, 2000. p. 43, (Manual Técnico do Instituto Pasteur, 4). 
8 WILBUR, L. A.; AUBERT, M. F. A. Épreuvre d'activité NIH. In: MESLIN, F-X.; KAPLAN, M. M.; KOPROWSKI, $\mathrm{H}$. Laboratoire techniques en la rage. 5. ed. Genève: Organisation Mondiale de la Santé, 1999. p. 366-374.

9 REED, L. J.; MÜENCH, H. A. A simple method of estimating fifty percent endpoints. The American Journal of Hygiene, v. 27, n. 3, p. 493-497, 1938.

10 SATO, G.; ITOU, T.; SHOJI, Y.; MIURA, Y.; MIKAMI, T.; ITO, M.; KURANE, I.; SAMARA, S. I.; CARVALHO, A. A.; NOCITI, D. P.; ITO, F. H.; SAKAI, I. Genetic and phylogenetic analysis of glicoprotein of rabies virus isolated from several species in Brazil. Journal of Veterinary Medical Science, v. 66, n. 7, p.747-753, 2004.

11 SATO, G.; TANAB, G. O.; SHOJI, Y.; ITOU, T.; ITO, F. H.; SATO, T.; SAKAI, T. Rapid discrimination of rabies viruses isolated from various host species in Brazil by multiplex reverse transcription-polymerase chain reaction. Journal of Clinical Virology, v. 33, p. 267-273, 2005.

12 HILLS, T. A. BioEdit: a user-friendly biological sequence alignment editor and analysis program for Windows95/98/NT. Nucleic Acids Symposium Series, v. 41, p. 95-98, 1999.

13 TAMURA, K.; DUDLEY, J.; NEI, M.; KUMAR, S. MEGA3: Integrated software for molecular evolutionary genetics analysis and sequence alignment. Briefings in Bioinformatics, v. 5, p. 150-163, 2004.

14 BERNARDI, F.; GOMES, A. A. B.; IT, F. H.; RICHTZENHAIN, L. J.; CORTEZ, A.; SAKAMOTO, S. M.; MAIORKA, P. C. Biological and immunological studies of five Brazilian rabies virus isolates. Brazilian Journal of Veterinary Research and Animal Science, $v$. 42, n. 4, p-307-312, 2005.

15 ZANETTI, C. R.; FRANCO, M. T. de; VASSÃO, R. C.; PEREIRA, C. A.; PEREIRA, O. A. C. Failure of protection induced by a brazilian vaccine against brazilian wild rabies viruses. Archives of Virology, v. 143, p. 17451756, 1998.

16 DIETZSCHOLD, B.; HOOPER, C. Human diploid cell culture rabies vaccine (HDCV) and purified chicken embryo cell culture rabies vaccine (PCECV) both confer protective immunity against infection with the silverhaired bat rabies virus strain (SHBRV). Vaccine, v. 16, n. 17, p. 1656-1659, 1998.

17 BARTH, R.; DIDERRICH, G.; WEINMANN, E. NIH test: a problematic method for testing potency of inactivated rabies vaccine. Vaccine, v. 6, p. 369377, 1988.
18 KOBAYASHI, Y.; SATO, G.; SHOI, Y.; SATO, T.; CUNHA, E. M.; SAMARA, S. I.; CARVALHO, A. A.; NOCITI, D. P.; ITO, F. H.; SAKAI, T. Molecular epidemiological analysis of bat rabies viruses in Brazil. The Journal of Veterinary Medical Science, v. 67, n. 7, p. 647-652, 2005.

19 KOBAYASHI, Y.; SATO, G.; KATO, M.; ITOU, I.; CUNHA, E. M.; SILVA, M. V.; MOTA, C. S.; ITO, F. $\mathrm{H}$; SAKAI, T. Genetic diversity of bat rabies in Brazil. Archives of Virology, v. 152, p. 1995-2004, 2007.

20 LANGONI, H.; HOFFMANN, J. L.; MENOZZI, B. D.; SILVA, R. C. da. Morcegos não-hematófagos na cadeia epidemiológica de transmissão da raiva. Veterinária e Zootecnia, v. 14, n. 1, p. 43-46, 2007.

21 ALBAS, A.; SOUZA, E. A. N. de; LOURENÇO, R. A.; FAVORETTO, S. R.; SODRÉ, M. M. Perfil antigênico do vírus da raiva isolado de diferentes espécies de morcegos não hematófagos da região de Presidente Prudente, Estado de São Paulo. Revista da Sociedade Brasileira de Medicina Tropical, v. 42, n. 1, p. 15-17, 2009.

22 ROMIJN, P. C.; VAN DER HEIDE, R.; CATTANEO, C. A. M.; SILVA, R. C. F.; VAN DER POEL, W. H. M. Study of Lyssaviruses of bat origin as a source of rabies for other animal species in the State of Rio de Janeiro, Brazil. American Journal of Tropical Medicine and Hygiene, v. 69, n. 1, p. 81-86, 2003.

23 VIEIRA, L. F. P. Caracterização molecular de vírus da raiva (Lyssavirus-Rhabdoviridade) isolados de espécimes clínicos de morcegos hematófagos Desmodus rotundus no Norte e Noroeste Fluminense. 2007. 85 f. Dissertação (Mestrado em Produção Animal) - Centro de Ciências e Tecnologias Agropecuárias, Universidade Estadual do Norte Fluminense, Campos dos Goytacazes, Rio de Janeiro, 2007.

24 HEINEMANN, M. B. Análise do polimorfismo do gene $\mathrm{N}$ de amostras de vírus da raiva isoladas no Estado de São Paulo. 2000. 56 f. Tese (Doutorado em Medicina Veterinária) - Faculdade de Medicina Veterinária e Zootecnia, Universidade de São Paulo, São Paulo, 2000.

25 KIMURA, L. M. S. Epidemiologia molecular de vírus da raiva em mamíferos silvestres e domésticos do Brasil. 2006. 94 f. (Doutorado em Vigilância Sanitária) Instituto Nacional de Controle de Qualidade em saúde, Fundação Oswaldo Cruz, Rio de janeiro, 2006.

26 COULON, P.;TERNAUX, J-P.; FLAMAND, A.; TUFFEREAU, C. An avirulent mutant of rabies virus is unable to infect motoneurons in vivo and in vitro. Journal of Virology, v. 72, n. 1, p. 273-278, 1998. 